Rincón Barón,m E.J., Zarate, D.A., Agudelo Castañeda, G.A., Cuarán, V.L., \& Passarelli, L.M. (2021). Micromorfología y ultraestructura de las anteras y los granos de polen en diez genotipos élite de Theobroma cacao (Malvaceae). Revista de Biología Tropical, 69(2), 403-421. DOI 10.15517/rbt. v69i2.44711

DOI 10.15517/rbt.v69i2.44711

\title{
Micromorfología y ultraestructura de las anteras y los granos de polen en diez genotipos élite de Theobroma cacao (Malvaceae)
}

\author{
Edgar Javier Rincón Barón ${ }^{1}$; (DD orcid.org/0000-0003-1347-171X \\ Diego A. Zarate ${ }^{2}$; (D) orcid.org/0000-0001-96303927 \\ Genaro Andrés Agudelo Castañeda ${ }^{2}$; (D) orcid.org/0000-0002-0469-1406 \\ Viviana Lucía Cuarán²; (iD orcid.org/0000-0001-7295-0046 \\ Lilian M. Passarelli³; (D) orcid.org/0000-0002-8870-8622
}

1. Grupo de Investigación Agroambiente y Salud-MICROBIOTA, Facultad de Ciencias de la Salud, Universidad de Santander, calle 70 No 55-210, Campus Universitario Lagos del Cacique, Bucaramanga, Colombia; ed.rincon@mail.udes.edu.co; ejrbaron@gmail.com

2. Corporación Colombiana de Investigación Agropecuaria-AGROSAVIA- Centro de Investigación La Suiza, Km. 32 , vía al mar, vereda Galápagos, Rionegro, Santander, Colombia; dzarate@agrosavia.co; gagudelo@agrosavia.co; vcuaran@agrosavia.co

3. Laboratorio de Estudios de Anatomía Vegetal Evolutiva y Sistemática (LEAVES), Facultad de Ciencias Naturales y Museo de La Plata, 64 entre 120 y diagonal 113, B1904 E, La Plata, Argentina; Impassarelli@yahoo.com.ar

Recibido 18-XI-2020. Corregido 17-I-2021. Aceptado 01-II-2021.

\author{
ABSTRACT \\ Micromorphology and ultrastructure of anthers and pollen grains in \\ ten elite genotypes of Theobroma cacao (Malvaceae).
}

Introduction: Despite the fact that T. cacao is an important species worldwide for cocoa production, little is known about the micromorphology and structure of anthers and pollen grains. Objectives: To describe and analyze the structure and micromorphology of the anthers and pollen grains of 10 elite genotypes of this important tropical species. Methods: More than 30 anthers of flowers in anthesis were taken of the 10 elite genotypes of $T$. cacao from the ex situ germplasm bank of the Suiza-Agrosavia Research Center (Rionegro, Santander-Colombia). The anthers with the pollen grains were fixated and processed according to the standard protocols for embedding and sectioning in paraffin. Sections obtained ( $3 \mu \mathrm{m}$ thick) were stained with SafraninAlcian blue to discriminate structures with primary and secondary walls and total polyphenols. Additionally, the samples were also stained with the PAS-Amidoblack technique was used to differentiate between structural and reserve polysaccharides as well as proteins. Toluidine blue staining was used for the determination of sporopollenin and polyphenols and finally Alcian blue-PAS-Hematoxylin staining was applied for additional descriptions. Observations were made using photonic microscopy and epifluorescence microscopy. For observation with scanning electron microscopy (SEM) the anthers with the pollen grains were fixed and dehydrated in 2.2 Dimethoxypropane, then desiccated to critical point and finally coated with gold. Results: the anthers are dithecal and supported by a long filament made up of an epidermal stratum, parenchymal tissue, and a vascular bundle. The dehiscence occurs longitudinally through the stomium. The anther wall is made up of a monostratified epidermal layer, followed by a layer of endothecial cells with lignified fibrillar thickenings, cellular remnants of tapetum and abundant orbicules can be seen covering the cavity of the microsporangia. The epidermal and parenchymal tissues of the anthers are abundant in polyphenols. Orbicules are generally spherical, psilated, and these exhibit the same staining and fluorescence reactions as exine from pollen grains. The pollen grains are monades, isopolar, small $(16-19 \mu \mathrm{m})$ with circular amb, spheroidal, tricolpate with medium or short colpi (5-10 
$\mu \mathrm{m})$ with sculptured membrane, semitectate, reticulated, heterobrochate, sculptured or non- sculptured walls, with microgranules of different size or scabrate. The statistical analyzes showed that there are significant differences in the size of the pollen grains $(\mathrm{P}<0.05)$. It is observed that the smallest pollen grains are those of the TCS 19 genotype $(16.890 \mu \mathrm{m})$ and are different from the other genotypes, and among these there are no significant differences. Only two genotypes (SCC 19 and SCA 6) showed pollenkit and only one has perforated walls (SCA 6). Conclusions: The structure and micromorphology of the anthers of T. cacao are similar to those described for other Malvaceae. Likewise, the pollen grains showed variations in size, ornamentation of the sporoderm and the lumen of the reticulum and the presence of pollenkitt. However, no relationship was observed between the micromorphological characters analyzed in the pollen grains and the pollen compatibility models reported for these genotypes.

Key words: cocoa; microornamentation; sporopollenin; histochemistry; palynology; pollenkitt.

Theobroma cacao L. es una planta ampliamente cultivada y distribuida en las zonas tropicales del mundo. Tradicionalmente estuvo circunscrita dentro de la familia Sterculiaceae. Sin embargo, estudios morfológicos, moleculares y biogeográficos la incluyeron dentro de la familia Malvaceae, junto con las familias Bombacaeae y Tiliaceae (Bayer et al., 1999; Bayer \& Kubitzki, 2003, Richardson, Whitlock, Meerow, \& Madriñán, 2015; Bhattacharjee, 2018). Bayer et al., (1999) y Bayer y Kubitzki (2003) indicaron que la familia Malvaceae está constituida por 9 subfamilias, Byttnerioideae, Grewioideae, Helicteroideae, Sterculideae, Brownlowioideae, Dombeyoideae, Malvoideae, Bombacoideae y Tilioideae. Bajo este nuevo enfoque de clasificación, T. cacao se circunscribe a la subfamilia Byttnerioidea.

T. cacao es originaria de la cuenca del Amazonas, en áreas relacionadas a los ríos Napo, Putumayo y Caquetá donde existe mayor variación de la especie (Zhang \& Motilal, 2016). De Suramérica pasó a Centroamérica, dispersándose quizás, a través de las rutas comerciales de los indígenas y luego de Mesoamérica fue llevado a Asia y Oceanía, llegando a África a través de los portugueses (Zhang \& Motilal, 2016). En la actualidad T. cacao es un cultivo tropical muy valioso dado que sus semillas son la materia prima para la industria de chocolates, para la producción de manteca y de cacao en polvo; estas industrias multimillonarias consumen la producción mundial anual de cacao estimada en 4 de millones toneladas (Squicciarini \& Swinnen, 2016; Wickramasuriya \& Dunwell, 2018). Entre los años 2015/2016 África contribuyó con el $74 \%$ de la producción mundial (2.92 millones de toneladas) seguido por América con $16 \%$ (0.64 millones de toneladas) y finalmente Asia y Oceanía con $10 \%$ (0.4 millones de toneladas) (Pipitone, 2016; Beg, Ahmad, Jan, \& Bashir, 2017; Wickramasuriya \& Dunwell, 2018).

T. cacao es un árbol de hojas simples perennes que puede alcanzar alturas entre 5-10 m; crece bien entre los 400 hasta 1250 $\mathrm{m}$ de altitud, con temperaturas entre 20 y 30 ${ }^{\circ} \mathrm{C}$ con una mínima de $16{ }^{\circ} \mathrm{C}$ y precipitaciones entre 1300 y $2800 \mathrm{~mm}$ por año (Bartley, 2005; de Almeida \& Valle, 2010; Nair, 2010). Las flores son caulinares y se desarrollan en partes del tallo denominadas cojinetes florales; éstas son perfectas, completas, heteroclamidias, con androceo en dos verticilos uno externo de cinco estambres funcionales y otro interno de cinco estambres estériles o estaminodios, por lo general de color púrpura (Bayer \& Kubitzki, 2003; Bartley, 2005; Swanson, Carlson, \& Guiltinan, 2008; Ha et al., 2016; de Souza, Moreira, Sarmento, \& da Costa, 2018). El gineceo está formado por un ovario súpero de cinco carpelos e igual número de lóculos, la placentación es axilar y el número de óvulos es variable (Bartley, 2005; Santos, Pires, \& Correa, 2012). En relación al fruto existe bastante controversia al momento de delimitar su categorización exacta, algunos autores lo han conceptualizado como una baya o drupa (Roth \& Lindorf, 1971). No obstante, el fruto estructural y funcionalmente parece estar más relacionado con una cápsula indehiscente (Simpson, 2010). T. cacao ha sido dividido en tres grandes grupos: el Criollo, el Forastero y el Trinitario, siendo este último un hibrido entre los dos primeros; 
esta división tiene en cuenta la morfología, características genéticas y orígenes geográficos (Bartley, 2005). Sin embargo, se han reconocido 10 agrupaciones genéticas, siendo morfológicamente variables (Motamayor et al., 2008). No obstante, recientes estudios han mostrado que Perú, Bolivia y Colombia pueden albergar poblaciones adicionales (Motamayor et al., 2010; Zhang et al., 2012; Osorio et al., 2017).

A pesar de que T. cacao es una especie económicamente importante para muchos países en el mundo, son escasos los trabajos relacionados con la comprensión de su biología reproductiva; algunos de estos tienen en cuenta el desarrollo y morfología floral, viabilidad del polen, polinizadores y mecanismos de autocompatibilidad y autoincompatibilidad (Bayer \& Kubitzki, 2003; Swanson et al., 2008; Ford \& Wilkinson, 2012; Rangel et al., 2012; Frimpong-Anin, Adjaloo, Kwapong, \& Oduro, 2014; Ha et al., 2016; Bridgemohan et al., 2017; Lanaud et al., 2017; N'Zi, Kahia, Diby, \& Kouamé, 2017; de Jesus Branco, da Silva, Lopes, \& Corrêa, 2018; López et al., 2018; Narayanapur, Suma, \& Minimol, 2018). En relación a los mecanismos ontogenéticos de la formación de los granos de polen, hasta el momento solo se documentan brevemente algunos aspectos de este proceso, por lo cual los eventos de la microesporogénesis en esta especie permanecen aún sin resolver (Sivachandran, Gnanam, Sudhakar, Suresh, \& Ram, 2017). En congruencia con lo anterior, la estructura y micromorfología de los granos de polen maduros de T. cacao han sido descritos pobremente y poco se conoce sobre sus implicaciones en la biología reproductiva y su impacto en los mecanismos de autoincompatibilidad (Halbritter \& Buchner, 2016; García, Bazurto, García, \& Zambrano, 2019). Atendiendo a estas razones, con este trabajo de investigación se realizará una descripción pormenorizada de la micromorfología y estructura de los granos de polen de 10 variedades élite de T. cacao presentes en el banco de germoplasma ex situ del centro de investigación la Suiza (Agrosavia, Santander, Colombia), haciendo énfasis en la microestructura de la pared de los granos de polen, presencia de orbículas, polenkit, presencia de gránulos de almidón en el citoplasma, anatomía y topografía de los polifenoles en las anteras y la relación entre el tapete y la formación de esporopolenina presente en la pared de los granos de polen.

\section{MATERIALES Y MÉTODOS}

Se tomaron más de 30 anteras de flores en antesis de cada uno de los genotipos élite de $T$. cacao, los cuales se describen en la Tabla 1 (Corporación Colombiana de Investigación Agropecuaria, 2014a; Corporación Colombiana de Investigación Agropecuaria, 2014b; Agudelo, Palencia, Antolinez, \& Báez, 2017). Las muestras fueron obtenidas del banco de germoplasma ex situ del Centro de Investigaciones La Suiza de la Corporación Colombiana de Investigación Agropecuaria (Agrosavia) ubicado en el Municipio de Rionegro, Santander-Colombia a $540 \mathrm{~m}$ de altitud (7²2'12" N \& 73'11'39" W) durante los meses de junio-julio del 2019. Los genotipos fueron seleccionados de acuerdo la a disponibilidad de materiales en el banco de germoplasma y teniendo en cuenta los modelos de compatibilidad polínica. Las anteras con los granos de polen se fijaron en una mezcla de formol, etanol y ácido acético (FAA) por 24-48 horas a $6{ }^{\circ} \mathrm{C}$. Posteriormente, se deshidrataron en una serie gradual de etanol y dos pasos de aclaramiento en Xilol (Ruzin, 1999) y se incluyeron en Paraplast plus (Mc Cormick ${ }^{\circledR}$ ) durante 12 horas a $55{ }^{\circ} \mathrm{C}$. Se obtuvieron secciones transversales y longitudinales con micrótomo rotatorio LEICA $\mathrm{RM}^{\circledR} 2125$, entre 3-4 $\mu \mathrm{m}$ de grosor. Se procedió a la tinción de las muestras con Safranina-azul de Alcian para distinguir estructuras con paredes primarias y secundarias y de manera no específica presencia de polifenoles totales. Adicionalmente, las muestras también fueron teñidas con la técnica de PAS, ácido peryódico de Schiff-Amidoblack para discriminar entre polisacáridos estructurales y de reserva, además de la presencia de proteínas. Para la determinación de esporopolenina y polifenoles se usó la tinción de azul de Toluidina 
TABLA 1

Genotipos élite de Theobroma cacao empleados en esta investigación. Se indica los modelos de compatibilidad polínica

TABLE 1

Elite genotypes of Theobroma cacao used in this research. Pollen compatibility models are indicated

$\begin{array}{ccc}\text { Genotipos élite de Theobroma cacao } & \text { Nombre } & \text { Compatibilidad polínica } \\ \text { TCS } 01 & \text { Theobroma Corpoica La Suiza } & \text { Autocompatible } \\ \text { TCS } 05 & \text { Theobroma Corpoica La Suiza } & \text { Autocompatible } \\ \text { TCS } 06 & \text { Theobroma Corpoica La Suiza } & \text { Autoincompatible } \\ \text { TCS } 11 & \text { Theobroma Corpoica La Suiza } & \text { Autoincompatible } \\ \text { TCS } 13 & \text { Theobroma Corpoica La Suiza } & \text { Autocompatible } \\ \text { TCS } 19 & \text { Theobroma Corpoica La Suiza } & \text { Autocompatible } \\ \text { SCC } 19 & \text { Selección Colombia Corpoica } & \text { Autocompatible } \\ \text { SCC } 61 & \text { Selección Colombia Corpoica } & \text { Autoincompatible } \\ \text { CCN } 51^{*} & \text { Colección Castro-Naranjal } & \text { Autocompatible } \\ \text { SCA 6** } & \text { Scavina } & \text { Autoincompatible }\end{array}$

TCS y SCC son genotipos colombianos. TCS and SCC are Colombian genotypes. * Testigo de autocompatibilidad. ** Testigo de autoincompatibilidad.

y finalmente se aplicó la tinción de azul de Alcian-PAS-Hematoxilina que determina la presencia de paredes primarias, polisacáridos y además de manera no específica polifenoles totales. Para todas las tinciones se procedió de acuerdo a literatura especializada (Ruzin, 1999; Elwers, Zambrano, Rohsius, \& Lieberei, 2010; Yeung, Stasolla, Sumner, \& Huang, 2015; Demarco, 2017; Rincón, Grisales, Cuaran, \& Cardona, 2020). Las secciones en parafina se examinaron con un microscopio fotónico Nikon 80 i eclipse ${ }^{\circledR}$ y Nikon eclipse Ni con el sistema de contraste diferencial de interferencia (CDI). Además, las secciones también fueron analizadas con fluorescencia, empleando el filtro de triple banda de excitación DAPI-FITCTexas, el cual incorpora un filtro de excitación con ventanas de paso de banda angostas en las regiones espectrales violeta $(395-410 \mathrm{~nm})$, azul $(490-505 \mathrm{~nm})$ y verde $(560-580 \mathrm{~nm})$. Las fotografías se obtuvieron con cámara digital Nikon DS-Fi1 ${ }^{\circledR}$ utilizando el programa NIS Elements versión 4.30.02 de Nikon.

Para llevar a cabo las descripciones morfológicas con microscopía electrónica de barrido (MEB), las anteras con los granos de polen fueron tomadas de la colección de germoplasma para fijarlas y deshidratarlas en 2.2
Dimetoxipropano acidificado por 2 a 3 días, realizando un cambio de este solvente durante este tiempo (Halbritter, 1998; Halbritter et al., 2018). Finalmente, se hicieron dos cambios en etanol absoluto durante 30 minutos cada uno, y procedió a desecar al punto crítico con un desecador SAMDRI®-795. Las muestras se montaron sobre cinta conductiva de carbono de doble cara y se recubrieron con oro en una ionizadora DENTON VACUUM DESK IV durante 10 minutos. Las observaciones y registro fotográfico se realizaron en un microscopio electrónico de barrido JEOL JSM-6490LV. Para las descripciones de los granos de polen y las anteras se utilizaron los términos sensu Halbritter et al., (2018), Punt, Hoen, Blackmore, Nilsson y Le Thomas (2007) y Crang, Lyons-Sobaski y Wise (2018). Las mediciones del tamaño de los granos de polen están representadas por la medida mínima, máxima, la media y la desviación estándar, empleando 10 réplicas por cada genotipo. Para evaluar si existen diferencias significativas en los tamaños de los granos de polen de los genotipos estudiados se le aplicaron las pruebas estadísticas ANOVA de un factor, evaluando el cumplimiento de los supuestos de normalidad (Shapiro-Wlik) y homogeneidad de varianzas (Test de Levene); 
al encontrarse diferencias significativas, se plantearon comparaciones pareadas múltiples a posteriori, empleando el test de LSD (Least significant difference) de Fisher con un nivel de significancia del $5 \%$ utilizando software estadístico R versión 4.0.2 (R Core Team, 2020).

Las descripciones con MEB se detallan para cada uno de los 10 genotipos estudiados. En contraste, en el curso del estudio realizado se comprobó que los genotipos utilizados presentan similar respuesta a las determinaciones histoquímicas efectuadas, por ello, para la descripción pormenorizada de estos procesos se eligieron los genotipos que suministraron las mejores imágenes o ilustraciones.

\section{RESULTADOS}

Las anteras: Las anteras de los diez genotipos estudiados son similares estructural y anatómicamente; estas son bitecas y se abren longitudinalmente a través del estomio (Fig. 1A, Fig. 1B). Están sostenidas por un filamento largo, formado por una capa uniestratificada de células epidérmicas y varios estratos de tejido parenquimatoso que protege el haz vascular (Fig. 1C). Tanto en la epidermis como en el parénquima de esta estructura, se aprecian vacuolas con grandes depósitos de polifenoles (Fig. 1C). La pared de las anteras maduras presenta externamente una capa uniestratificada de células epidérmicas, que por lo general son de contorno rectangular, aunque algunas se aprecian de contorno cuadrado y con la maduración tienden a aplanarse; estas células pueden presentar depósitos abundantes de polifenoles en las vacuolas que llegan a obliterar por completo el citoplasma (Fig. 1D).

Debajo de la epidermis, se localiza el endotecio que corresponde a una capa uniestratificada de células cuadradas altas con engrosamientos fibrilares lignificados (Fig. 1D), estas células rara vez presentan depósitos de polifenoles. Internamente al endotecio, las anteras maduras tienen una capa uniestratificada de células que se aprecian colapsadas y en degradación, estos remanentes celulares corresponden al tapete (Fig. 1D). Sobre las paredes de estos remanentes celulares se observa el depósito masivo de orbículas que recubren toda la pared de los lóculos de los microesporangios (Fig. 2D, Fig. 2E). Las orbículas o cuerpos de Ubish en los genotipos analizados de T. cacao se presentan en la pared de las anteras o sobre los granos de polen, tienen diferentes formas y tamaños, aunque se aprecian principalmente esféricas y por lo general son psiladas, estas estructuras miden entre 0.42-1.14 $\mu \mathrm{m}$ (Fig. 1E). Las orbículas presentan los mismos patrones de fluorescencia que la exina de los granos de polen cuando son observados utilizando una tinción específica y un filtro fluorescente determinado; tal es el caso cuando se utiliza el filtro de triple banda de excitación DAPIFITC-Texas y la tinción azul de Alcian-Hematoxilina, en estas condiciones, las orbículas y el esporodermo se distinguen de color verde, en tanto que los polifenoles se aprecian de color amarillo (Fig. 1F). En contraste, cuando se emplea este mismo filtro, pero con la tinción de PAS-Amidoblack las orbículas y la pared de los granos de polen se ven de color azulverdoso y los polifenoles se aprecian de color rojizo (Fig. 1G). Cuando estos mismos componentes se aprecian en campo claro utilizado la tinción de azul de Toluidina la pared de los granos de polen y las orbículas se aprecian de azul turquesa y los polifenoles se ven de color marrón oscuro e incluso negros (Fig. 1D). Adicionalmente, se pudo observar que el conectivo que une las dos tecas está formado principalmente por células parenquimatosas con grandes depósitos de polifenoles y drusas de oxalato de calcio (Fig. 1D).

En todos los genotipos de T. cacao analizados se observó la presencia de abundantes gránulos de almidón en el citoplasma de los granos de polen, en tanto que, en los tejidos de las anteras, no se pudo evidenciar la presencia de este carbohidrato (Fig. 1H). Así mismo, no fue posible detectar proteínas en las células o tejidos que forman las anteras con la técnica de tinción de PAS-Amidoblack.

Los granos de polen: En todos los genotipos de T. cacao analizados, los granos de 


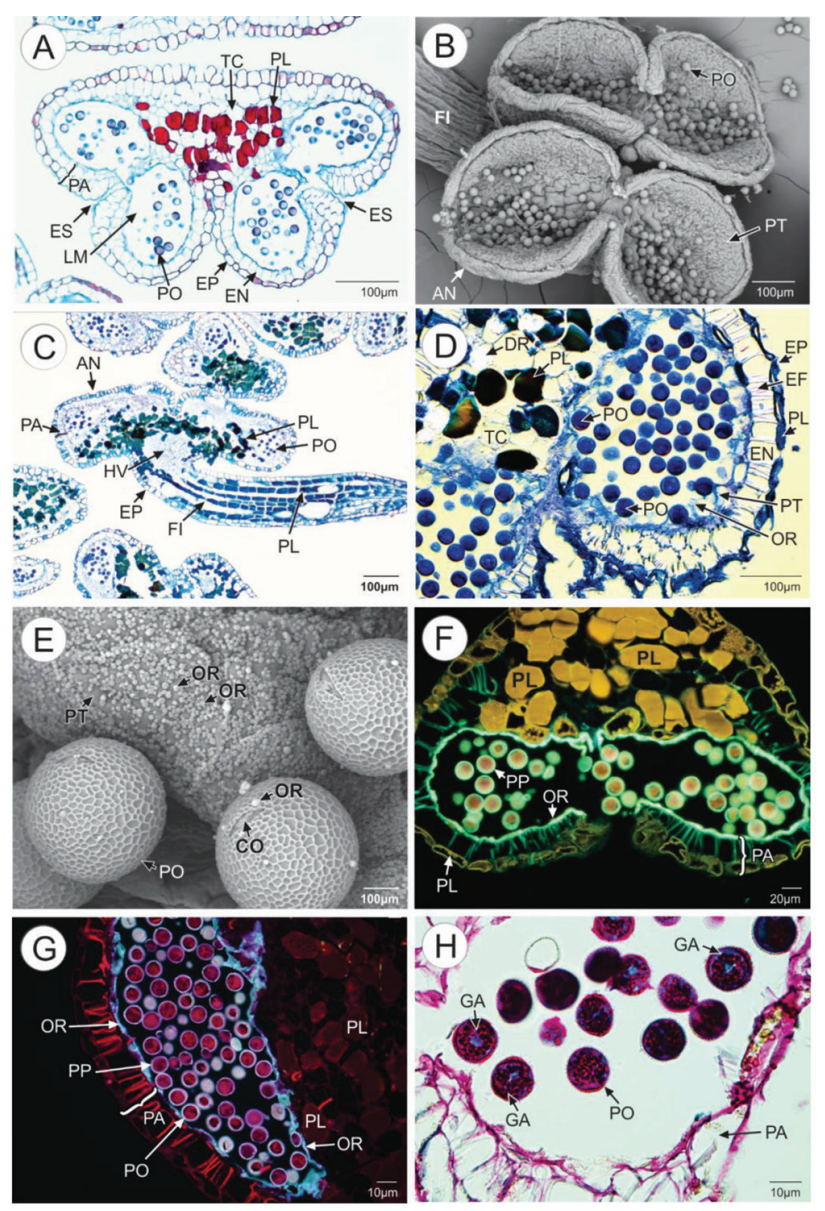

Fig. 1. Características anatómicas e histoquímicas de las anteras y granos de polen de Theobroma cacao. A. Sección transversal de las anteras (Safranina-azul de Alcian). Se aprecia la pared de las anteras, los lóculos de los microesporangios y el estomio. B. Anteras vistas en microscopía electrónica de barrido (MEB). Se aprecian los granos de polen y el filamento. C. sección longitudinal del filamento que sostiene las anteras (azul de Toluidina). D. Pared de las anteras maduras. Se aprecia la epidermis, endotecio, restos del tapete con orbículas y los granos de polen (azul de Toluidina). E. Granos de polen y orbículas en las anteras (MEB). F. Sección trasversal de las anteras. Se aprecian los polifenoles y las orbículas cubriendo la cavidad de los lóculos (Filtro DAPI-FITC-Texas, azul de Alcian-Hematoxilina). G. Sección trasversal de las anteras. Se aprecian las orbículas cubriendo la cavidad de los lóculos (Filtro DAPI-FITC-Texas, PAS-Amidoblack). H. Sección transversal de los granos de polen. Los gránulos de almidón se aprecian en color fucsia (PAS-Amidoblack). AN: antera; CO: colpo; DR: drusas; EF; engrosamientos fibrilares; EN: endotecio; EP: epidermis; ES: estomio; FI: filamento; GA: gránulos de almidón; HV: haz vascular; LM: lóculo del microesporangio; OR: orbículas; PA: pared de la antera; PL: polifenoles; PO: polen; PP: pared del grano de polen; PT: paredes remanentes del tapete; TC: Tejido conectivo.

Fig. 1. Anatomical and histochemical characteristics of the anthers and pollen grains of Theobroma cacao. A. Cross section of the anthers (Safranina-Alcian blue). The wall of the anthers, the locules of the microsporangia and the stomium can be seen. B. Anthers seen in scanning electron microscopy (SEM). Pollen grains and filament are appreciated. C. Longitudinal section of the filament supporting the anthers (Toluidine blue). D. Wall of mature anthers. Epidermis, endothecium, remains of the tapetum with orbicules and pollen grains (Toluidine blue) can be seen. E. Pollen grains and orbicules on anthers (SEM). F. Cross section of the anthers. Polyphenols and orbicules covering the cavity of the locules are seen (DAPI-FITCTexas Filter, Alcian Blue-Hematoxylin). G. Cross section of the anthers. Orbicules can be seen covering the cavity of the locules (DAPI-FITC-Texas Filter, PAS-Amidoblack). H. Cross section of pollen grains. Starch granules are seen in fuchsia color (PAS-Amidoblack). AN: anther; CO: colpus; DR: druses; EF; fibrillar thickenings; EN: endothecium; EP: epidermis; ES: stomium; FI: filament; GA: starch granules; HV: vascular bundle; LM: microsporangium locule; OR: orbicules; PA: anther wall; PL: polyphenols; PO: pollen; PP: pollen grain walls; PT: tapetum walls remaining; TC: connective tissue. 

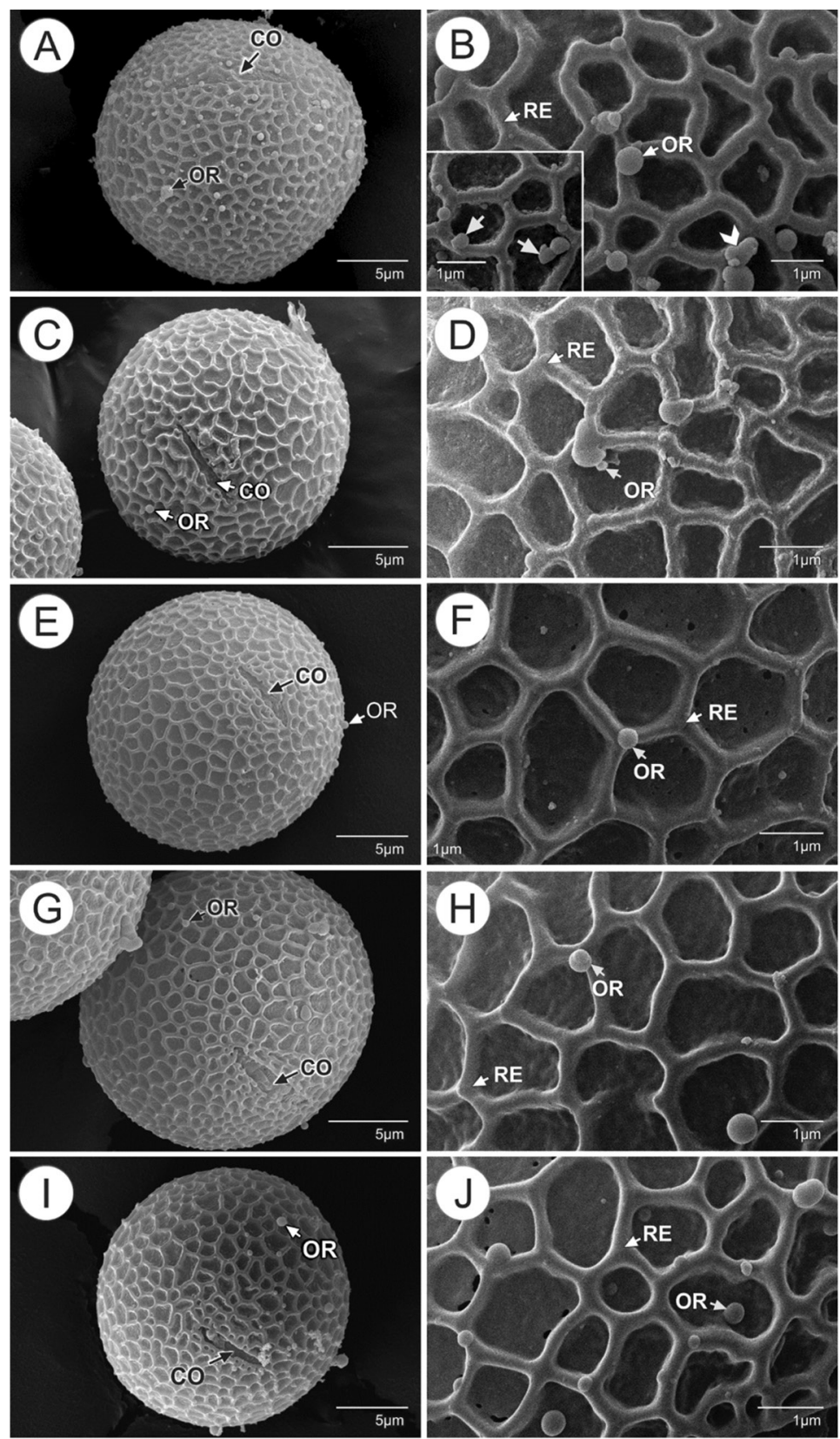

Fig. 2. Granos de polen y detalles micromorfológicos de los genotipos de Theobroma cacao. Se observan los colpos y las orbículas sobre la superficie del retículo. A, B. Theobroma Corpoica La Suiza TCS 01. A. vista ecuatorial. En B. el detalle indica orbículas con microgranulaciones (flechas) y la cabeza de flecha orbículas fusionadas. C, D. Theobroma Corpoica La Suiza TCS 05. C. vista ecuatorial. E, F., E. vista ecuatorial. Theobroma Corpoica La Suiza TCS 06. G, H. Theobroma Corpoica La Suiza TCS 11. I, J. Theobroma Corpoica La Suiza TCS 13. CO: colpo; OR: orbículas; RE: retículo

Fig. 2. Pollen grains and micromorphological details of Theobroma cacao genotypes. Colpi and orbicules are observed on the surface of the reticulum. A, B. Theobroma Corpoica La Suiza TCS 01. A. equatorial view. In B. the detail indicates orbicules with microgranulations (arrows) and the arrowhead orbicules fused. C, D. Theobroma Corpoica La Suiza TCS 05. C. equatorial view. E, F. Theobroma Corpoica La Suiza TCS 06. E. equatorial view. G, H. Theobroma Corpoica La Suiza TCS 11. I, J. Theobroma Corpoica La Suiza TCS13. CO: colpus; OR: orbicules; RE: reticulum 
polen son monades, isopolares, pequeños (16$19 \mu \mathrm{m}$ ) con amb circular (ámbito o contorno del grano de polen en vista polar), esferoidales, tricolpados con colpos medianos o breves (5-10 $\mu \mathrm{m})$ con membrana ornamentada, semitectados, reticulados, heterobrochados, muros ornamentados o sin ornamentación, lumen con microgránulos de diferente tamaño, se observa que el retículo disminuye de tamaño hacia las aberturas (Fig. 2, Fig. 3). Adicionalmente, se observó que el genotipo SCA 6 presenta perforaciones en los muros (Fig. 3J). Los genotipos SCC 19 y SCA 6 muestran abundante polenkit o cemento polínico (Fig. 3C, Fig. 3D, Fig. 3I, Fig. 3J). Las orbículas sobre los granos de polen se aprecian solitarias o a veces pueden quedar fusionadas en 2 o 3 unidades (Fig. 2B, Fig. 3A, Fig. 3F). Aunque la superficie de las orbículas por lo general es psilada, en los genotipos TCS 01 y SCC61 pueden presentarse además microgranuladas (Fig. 2B, Fig. 3F). Los análisis estadísticos mostraron con un nivel de confianza del $95 \%$ que existen diferencias significativas en el tamaño de los granos de polen según los genotipos analizados $(\mathrm{P}<0.05)$. Se observa que los granos de polen con menor tamaño son los del genotipo TCS 19 (16.890 $\mu \mathrm{m})$ y son diferentes de los demás genotipos. No se observan diferencias significativas en los genotipos SCA 6, TCS 05, TCS 13, TCS 06, CCN 51, TCS 01. Tampoco se observan diferencias entre los genotipos SCC 61, TCS11 y SCC 19 (los de mayor tamaño). De igual forma, los genotipos TCS 11, SCC 19, TSC 01 y CCN 51 no presentan diferencias significativas. Las principales características analizadas en los granos de polen se resumen en la Tabla 2.

\section{DISCUSIÓN}

La pared de las anteras maduras de $T$. cacao presenta una epidermis persistente, un endotecio con engrosamientos fibrilares que se encuentra recubierto por restos de las paredes tapetales, este patrón histológico básico, es común en las anteras maduras y dehiscentes de la mayoría de las angiospermas (Passarelli \& Cocucci, 2006; Wilson, Song, Taylor, \&
Yang, 2011; Wei, Xu, \& Li, 2015; Shamrov, Anisimova, \& Babro, 2020), incluido Malvaceae (Tang, Gao, Wang, \& Chen, 2006; Galati, Monacci, Gotelli, \& Rosenfeldt, 2007; Tang, Gao, \& Xie, 2009; Lattar, Galati, \& Ferruci, 2014). Concordando con las observaciones de Manning (1996), los engrosamientos fibrilares presentes en el endotecio de los genotipos de T. cacao son el tipo anular y es similar a lo registrado para varias especies dentro de la familia Malvaceae (Lattar et al., 2014); aunque no son exclusivos de este grupo de plantas (French, 1985; Manning \& Linder, 1990; Manning, 1996; Tebbitt \& Maciver, 1999; Carrizo, 2002; Nakamura, Longhi-Wagner, \& Scatena, 2010; Gotelli, Galati, \& Zarlavsky, 2016). Estos engrosamientos fibrilares del endotecio de T. cacao son fuertemente lignificados dando respuesta positiva con azul de Toluidina, lo cual es similar a lo observado para otras especies de plantas (Dawson, et al., 1999; Wilson et al., 2011).

Los procesos de amilogénesis y amilólisis en las anteras de las plantas presentan variaciones que dependen del momento del desarrollo de las mismas, y más aún se pueden presentar variaciones dependiendo el grupo de plantas que se analice (Pacini \& Franchi, 1988; Pacini, Guarnieri, \& Nepi, 2006; Santos de Oliveira, Martins, Dorneles, \& Carvalho de Freitas, 2015). Por lo general, en las anteras maduras y dehiscentes, los tejidos parietales como la epidermis y el endotecio, no presentan almidones para este momento del desarrollo (Konyar, Dane, \& Tütüncü, 2013; Santos de Oliveira et al., 2015; Wei et al., 2015; Yun \& Huiqiao, 2015; Zheng, Su, Xiao, \& Tian, 2017), estas observaciones también se cumplen para los genotipos de T. cacao.

Baker y Baker (1979) han indicado la presencia de granos de polen maduros con y sin gránulos de almidón en el citoplasma en diferentes grupos de plantas. Las especies con granos de polen pequeño, por lo general, presentan abundantes almidones y una viabilidad temporal reducida, al momento de su dispersión. Por el contrario, las especies con polen de mayor tamaño, por lo general, son carentes 

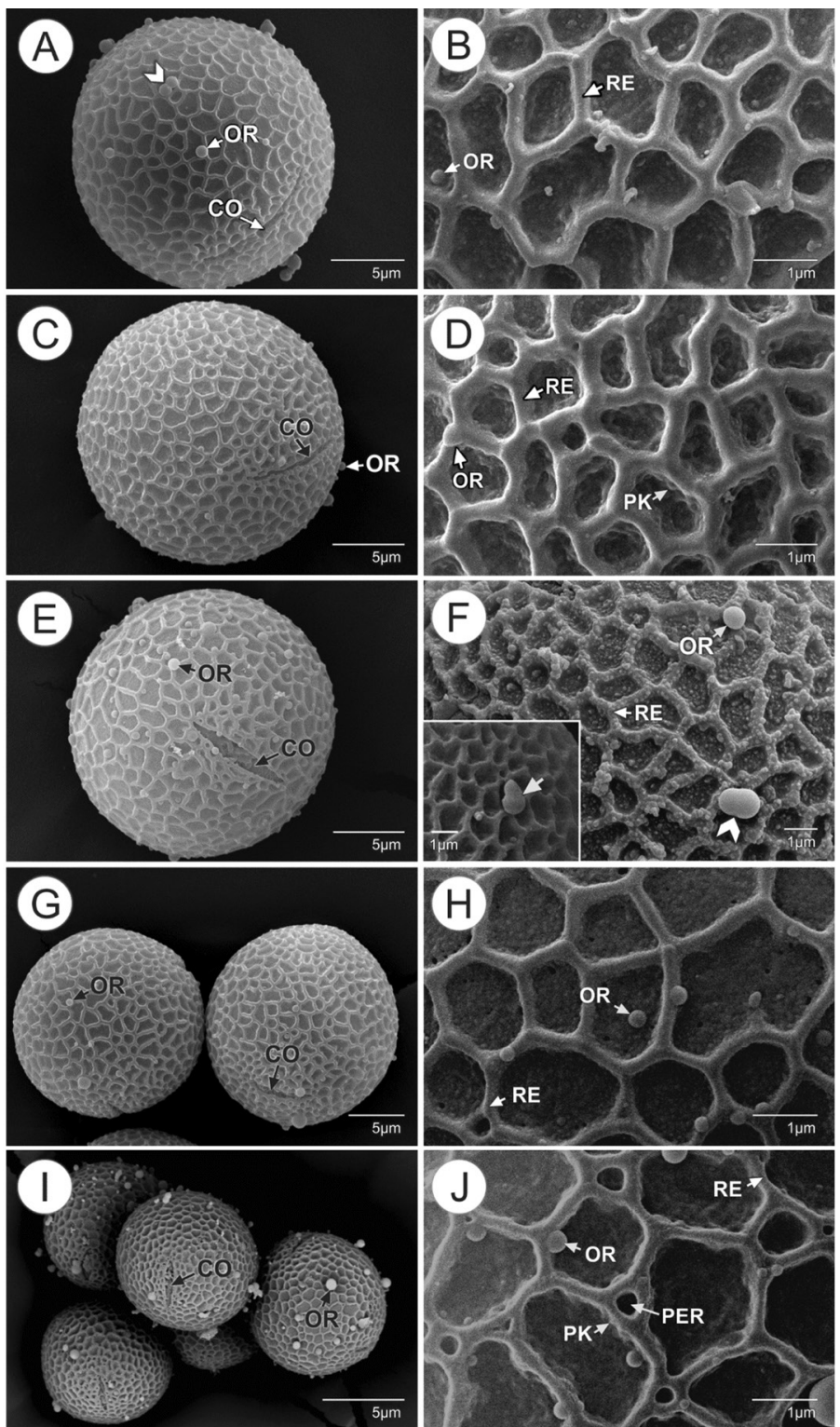

Fig. 3. Granos de polen y detalles micromorfológicos de los genotipos de Theobroma cacao. Se observan los colpos y las orbículas sobre la superficie del retículo. A, B. Theobroma Corpoica La Suiza TCS 19. En A. (vista ecuatorial) la cabeza de flecha indica dos orbículas fusionadas. C, D. Selección Colombia Corpoica SCC 19. E, F. Selección Colombia Corpoica SCC 61. E. vista ecuatorial. La cabeza de flecha en F. muestra dos orbículas fusionadas y el detalle indica orbículas con microgranulaciones (flecha). G, H. Colección Castro-Naranjal CCN 51. G. a la izquierda, orbícula sobre el polo; a la derecha se observa en vista ecuatorial el colpo. I, J. Scavina SCA 6. CO: colpo; OR: orbículas; RE: retículo; PER: perforaciones; PK: pollenkit.

Fig. 3. Pollen grains and micromorphological details of Theobroma cacao genotypes. Colpi and orbicules are observed on the surface of the reticulum. A, B. Theobroma Corpoica La Suiza TCS 19. In A. (equatorial view) arrowhead indicates two fused orbicules. C, D. Selección Colombia Corpoica SCC 19. E, F. Selección Colombia Corpoica SCC 61. E. equatorial view. The arrowhead in $\mathbf{F}$. shows two fused orbicules and the detail indicates orbicules with microgranulations (arrow). G, H. Colección Castro-Naranjal CCN 51. G. on the left, orbicule on the pole; on the right colpus in the equatorial view I, J. Scavina SCA 6. CO: colpus; OR: orbicules; RE: reticulum; PER: perforations; PK: pollenkitt. 


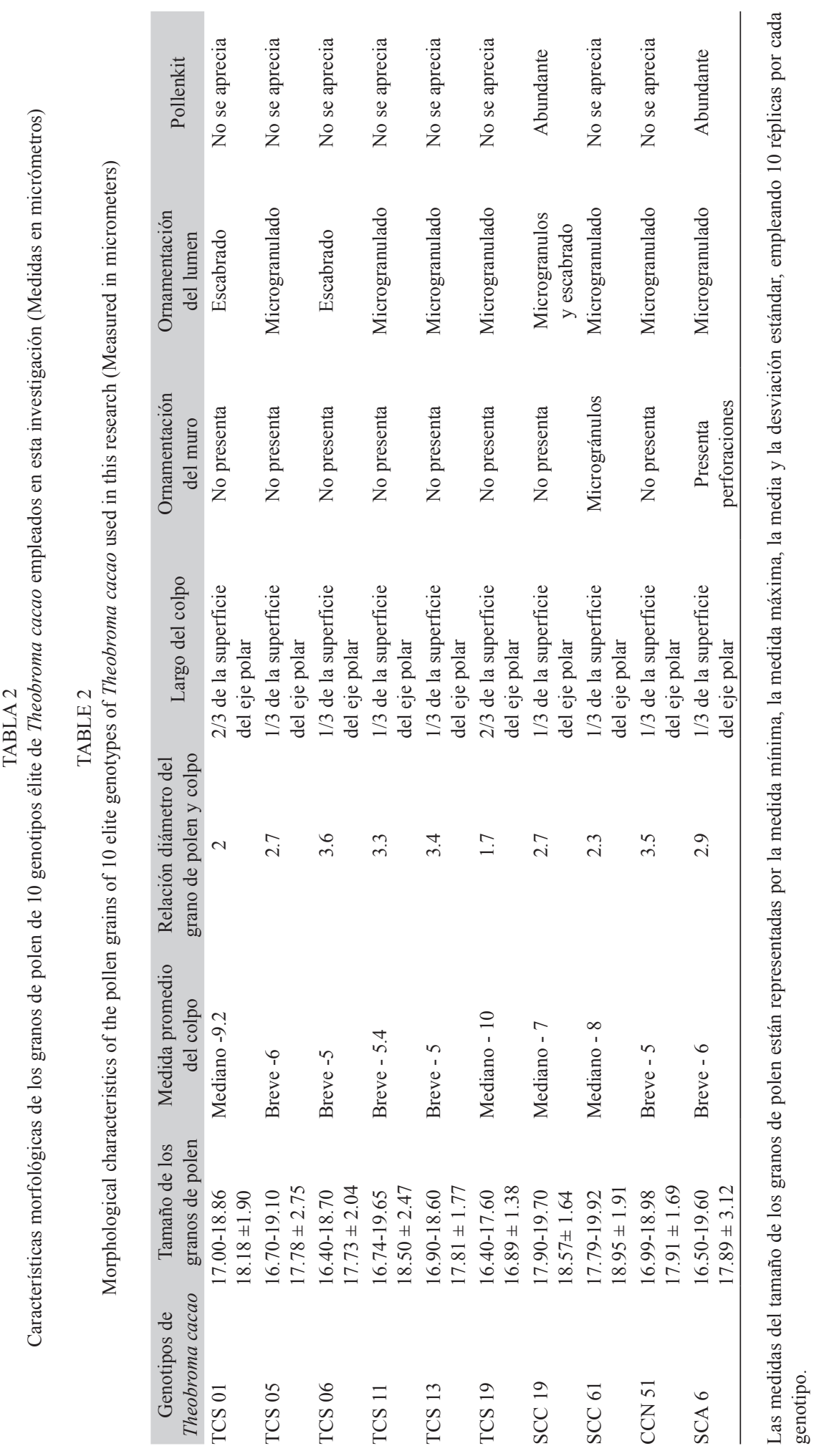


de almidones, pero abundantes en carbohidratos solubles, e incluso lípidos y se consideran de una viabilidad temporal mayor (Santos de Oliveira et al., 2015). De acuerdo con las observaciones de la gran cantidad de gránulos de almidón en el citoplasma de los genotipos de $T$. cacao y el tamaño reducido de los granos de polen $(<20 \mu \mathrm{m})$, se puede concluir que esta especie presenta una viabilidad temporal reducida, y en este sentido la dispersión de los granos de polen, una vez se da su liberación de la antera, cuenta con una corta ventana de tiempo antes de que la viabilidad se vea afectada. Lo anterior es congruente con observaciones sobre la biología de la polinización de $T$. cacao, ya que el polen es de corta viabilidad, y esta puede ser de unos pocos minutos hasta varios días (García et al., 2019). No obstante, además del genotipo, factores ambientales como la humedad, la temperatura y otros factores abióticos, pueden influenciar esta situación (García, Vera, Zambrano, Zamora, \& Cedeño, 2020)

Aunque no se sabe con exactitud la función de las orbículas, al parecer están relacionadas con la dispersión del polen (Heslop-Harrison, 1968). Así, Galati, Gotelli, Rosenfeldt, Torretta y Zarlavsky (2011) han relacionado la presencia de orbículas espiculadas y equinuladas con especies de polinización anemófila y también con la polinización vibratoria (Galati, Gotelli, Dolinko, \& Rosenfeldt, 2019). En tanto que, las orbículas psiladas, se pueden relacionar con especies melitófilas y las orbículas psiladas y perforadas por lo general con la polinización ornitófila (Galati et al., 2011). En este sentido y debido a la presencia de orbículas esféricas y psiladas, se confirma que $T$. cacao es una especie miófila, polinizada por Ceratopogónidos, con síndrome de polinización que incluye flores estructuralmente complejas, con nectarios en los pedicelos, sépalos y ovarios, estaminodios y lígulas coloreadas y además reflectancia/absorbancia en el espectro UV que le sirven como atrayentes a sus polinizadores (Young, Schaller, \& Strand, 1984; Young, Erickson, Strand, \& Erickson, 1987; Bayer \& Kubitzki, 2003).
Strittmatter y Galati (2001), Galati et al., 2007 y Galati et al., (2011) indican que las orbículas de varias especies de plantas se pueden presentar aglomeradas sobre las paredes internas del endotecio o sobre los restos de las paredes del tapete, recubriendo la superficie del lóculo microesporangial; además de presentar las mismas reacciones de tinción y autofluorescencia que el esporodermo de los granos de polen, lo que estaría reflejando su composición de esporopolenina; estas observaciones concuerdan con lo descrito en esta investigación para los 10 genotipos analizados de $T$. cacao y es congruente con lo indicado recientemente para diferentes grupos de plantas (Ruggiero \& Bedini, 2020) y en particular para Malvaceae (Lattar et al., 2014). Las orbículas de T. cacao pueden ser variables en tamaño, por lo general son psiladas y se pueden presentar solitarias y a veces fusionadas, estas características han sido indicadas para varios grupos de plantas (Huysmans, El-Ghazaly, Nilsson, \& Smets, 1997; Galati, 2003) incluidas Malvaceae (Galati \& Rosenfeldt, 1998; Lattar et al., 2014). Aunque Galati y Rosenfeldt, (1998) y Lattar et al., (2014) también consideran la presencia de orbículas con microgranulaciones en algunas de las especies de Malvaceae y esto concuerda con nuestras observaciones para los genotipos TCS 01 y SCC61 de T. cacao. Adicionalmente, también se ha indicado la presencia de orbículas de contorno piriforme en Malvaceae (Strittmatter, Galati, \& Monacci, 2000; Galati et al., 2007)

Con la información obtenida de esta investigación no fue posible determinar si el tapete $T$. cacao es secretor, invasivo no sincitial o plasmodial, dado que se tomaron anteras maduras y en dehiscencia, momento del desarrollo para el cual el tapete ha degenerado por completo (Pacini, Franchi, \& Hesse, 1985; Parkinson \& Pacini, 1995; Furness \& Rudall, 2001; Galati et al., 2007; Pacini, 2010; Wei et al., 2015). En congruencia con lo anterior, varios autores han indicado la relación exclusiva entre la presencia de orbículas y el tapete secretor (Pacini et al., 1985; Huysmans, El-Ghazaly, \& Smets, 1998; Verstraete, Moon, Smets, \& Huysmans, 2014). Por el contrario, se ha observado la 
presencia de orbículas en especies con tapete plasmodial (Gotelli, Galati, \& Medan, 2008). En el caso de Malvaceae, el tapete secretor es el más común (Lattar et al., 2014), pero se ha registrado en esta familia de plantas la presencia de orbículas en especies que tienen tapete plasmodial e invasivo no sincitial (Strittmatter \& Galati, 2001; Galati et al., 2007; Galati et al., 2011). Teniendo en cuenta lo anterior, se puede indicar que las orbículas se encuentran ampliamente distribuidas en diferentes grupos de plantas (Verstraete et al., 2014; Moon, 2018; Ruggiero \& Bedini, 2020) y la relación entre estas estructuras y los tipos de tapete, no ha sido aún claramente dilucidada.

Los polifenoles son metabolitos secundarios presentes en la mayoría de las plantas, están relacionados con respuesta a la herbivoría, también como mecanismos de resistencia a hongos y como subproductos de algunos procesos metabólicos (Lattanzio, Lattanzio, \& Cardinali, 2006; Aoun, Rioux, Simard, \& Bernier, 2009; Aoun, 2017; Rincón et al., 2020). Estos compuestos, han sido registrados ampliamente en T. cacao (Porter, Ma, \& Chan, 1991; Rojas et al., 2008; Rangel et al., 2012; Ioannone et al., 2015; Gallego, Henao, Urrea, \& Atehortua, 2016; Magrone, Russo, \& Jirillo, 2017; Alean et al., 2020) y su función en T. cacao, probablemente se relacione con lo descrito para otras plantas. En este sentido, Garcia, Potiguara, Kikuchi, Demarco y Aguiar (2014) relacionan la presencia de compuestos polifenólicos y cristales de oxalato de calcio tipo drusas como respuesta a la herbivoría y mecanismos de resistencia a hongos como Moniliophthora perniciosa (Stahel) (Aime \& Phillips-Mora, 2005). Adicionalmente, los polifenoles junto con otros compuestos son los responsables del color y sabor del chocolate (Porter et al., 1991; Counet, Ouwerx, Rosoux, \& Collin, 2004; Niemenak, Rohsius, Elwers, Ndoumou, \& Lieberei, 2006; Oracz, Zyzelewicz, \& Nebesny, 2015; Magrone et al., 2017). Se ha registrado para Theobroma, que los polifenoles se acumulan en las vacuolas principalmente de tejidos epidérmicos y parenquimatosos (Martini, Figueira, Lenci, \& Tavares, 2008; Elwers et al., 2010;
Garcia et al., 2014; Alean et al., 2020) lo cual es congruente con las observaciones anatómicas realizadas en este trabajo para las anteras y filamentos de los estambres de los genotipos analizados de T. cacao.

En general, los granos de polen de todos los genotipos analizados de T. cacao tienen características micromorfológicas similares; son de contorno esféricos, pequeños, tricolpados, reticulados, heterobrocados y con presencia de orbículas, estos hallazgos son coincidentes con las observaciones previas para esta especie (Halbritter \& Buchner, 2016; García et al., 2019). Sin embargo, algunos detalles micromorfológicos como la complejidad de la ornamentación de los muros del retículo, del lumen y la ornamentación de la membrana de los colpos, así como la presencia de polenkit, se describen en detalle en esta investigación para T. cacao. En general, el tamaño de los granos de polen de los genotipos analizados no supera los $20 \mu \mathrm{m}$ y esto es coincidente con lo que Erdtman (1986) categoriza como polen pequeño y es similar con lo observado por Enríquez (1985) y García et al., (2019) para T. cacao.

La familia Malvaceae es euripalínica, y con la estructura y micromorfología de los granos de polen diversa, se ha registrado polen de contorno esférico, prolado, oblado y variación de estos contornos. Las aberturas pueden ser colpadas, colporadas o poradas, en tanto que la ornamentación va desde reticulada, equinulada, foveolada o variación de estos patrones (Bayer \& Kubitzki, 2003; Perveen, Grafström, \& ElGhazaly, 2004; Perveen \& Qaiser, 2009; Bibi, Naveed, Manzoor, \& Ajab, 2010; Hamdy \& Shamso, 2010; Mambrín, Avanza, \& Ferrucci, 2010; Saba \& dos Santos, 2015; Halbritter \& Buchner, 2016; Silveira Júnior, Lima e Lima, \& Saba, 2017; Amirul-aiman et al., 2019). Para la subfamilia Byttneridoideae a la cual se circunscribe T. cacao, Hamdy y Shamso (2010) han descrito dos tipos polínicos: el tipo Abroma característico de la tribu Byttnerieae que presenta polen tricolpado, en tanto que el tipo Brachychiton presente en la tribu Theobromeae caracterizado por tener polen tricolporado. Por otro lado, los estudios realizados por 
Silveira Júnior et al., (2017) en Waltheria L. (Malvaceae-Byttnerioideae) muestran una gran variabilidad en las aberturas (colporados, pantoporados y pantocolporados) pero no se observan granos colpados. De acuerdo a nuestras observaciones de los diez genotipos de T. cacao indican que los granos de polen son afines con el tipo Abroma por la presencia de tres colpos.

Analizando los caracteres micromorfológicos de los granos de polen de los genotipos y su relación con los modelos de compatibilidad polínica, no se encontró una relación específica, por ejemplo, se observaron genotipos autoincompatibles y autocompatibles que tienen muros ornamentados y sin ornamentación; lo mismo, se cumple para los tipos de ornamentación microgranulada y escabrada presente en el lumen del retículo. Lo anterior, también se aplica para las medidas tomadas como: el tamaño de los granos de polen, la medida promedio del colpo, la relación diámetro del grano de polen y colpo y el largo del colpo. El polenkit fue abundante en los genotipos SCC 19 (autocompatible) y SCA 6 (autoincompatible) y no se pudo observar en los demás genotipos; sin embargo, es importante entender que $T$. cacao es una especie polinizada por insectos en especial por dípteros (Kaufmann, 1975; Young et al., 1984; Young et al., 1987; Young \& Severson, 1994; Adjaloo \& Oduro, 2013; Bridgemohan et al., 2017; Chumacero de Schawe, Kessler, Hensen, \& Tscharntke, 2018) lo que implica probablemente, la presencia de polenkit en todo los genotipos (Pacini \& Hesse, 2005), y más aún cuando se ha documentado que el procesamiento de los granos de polen para su observación con MEB utilizando 2.2 dimetoxipropano y secado al punto crítico puede eliminar esta estructura de la superficie de los granos de polen (Pacini \& Hesse, 2005; Halbritter et al., 2018). Todas las observaciones anteriores reforzarían la idea de que la autoincompatibilidad de T. cacao es del tipo tardía y está relacionada con la fusión del núcleo espermático del grano de polen y el núcleo de la ovocélula en el saco embrionario (Ford \& Wilkinson, 2012; Lanaud et al., 2017; N'Zi et al., 2017; de Jesus Branco et al., 2018; Narayanapur et al., 2018).
Más aun, se ha documentado que el polen de las especies autoincompatibles puede germinar sobre sus estigmas y formar un tubo polínico viable (N'Zi et al., 2017).

Declaración de ética: los autores declaran que todos están de acuerdo con esta publicación y que han hecho aportes que justifican su autoría; que no hay conflicto de interés de ningún tipo; y que han cumplido con todos los requisitos y procedimientos éticos y legales pertinentes. Todas las fuentes de financiamiento se detallan plena y claramente en la sección de agradecimientos. El respectivo documento legal firmado se encuentra en los archivos de la revista.

\section{AGRADECIMIENTOS}

Los autores agradecen a las siguientes instituciones y personas: a la Universidad de Santander (UDES) y a la Corporación Colombiana de Investigación Agropecuaria (AGROSAVIARecomendaciones técnicas de sistemas alternativos de producción intensiva y tradicionales de Cacao con énfasis en Arreglos Agroforestales (SAF), En especial a Jairo Rojas Molina por la redacción final del proyecto SAF) por el apoyo financiero al trabajo de investigación. Al Laboratorio de Biotecnología de la Universidad de Antioquia (UDEA) por facilitarnos el microscopio fotónico para la toma de algunas imágenes. A Deicy Villalba Rey (UDES) por su valiosa colaboración con los análisis estadísticos realizados.

\section{RESUMEN}

Introducción: a pesar de que $T$. cacao es una especie importante a nivel mundial por la producción de cacao, es poco lo que se conoce sobre la micromorfología y estructura de las anteras y los granos de polen. Objetivos: Describir y analizar la estructura y micromorfología de las anteras y los granos de polen de 10 genotipos élite de esta importante especie tropical. Métodos: Se tomaron más de 30 anteras de flores en antesis de los 10 genotipos élite de T. cacao del banco de germoplasma ex situ del Centro de Investigaciones Suiza-Agrosavia (Rionegro, SantanderColombia). El material se procesó de acuerdo con los 
protocolos estándar para embeber y seccionar en parafina. Las secciones obtenidas $(3 \mu \mathrm{m})$ se tiñeron con azul de Safranina-Alcian para discriminar estructuras con paredes primarias y secundarias y polifenoles totales. Además, se usó la técnica PAS-Amidoblack para diferenciar entre polisacáridos estructurales y de reserva, así como proteínas. Para la determinación de esporopolenina y polifenoles se usó la tinción azul de toluidina y finalmente para descripciones adicionales se aplicó la tinción azul alcián-PAShematoxilina. Las observaciones se realizaron mediante microscopio fotónico y microscopio de epifluorescencia. Para la observación con microscopía electrónica de barrido (MEB), las anteras con los granos de polen se fijaron y deshidrataron en 2.2 dimetoxipropano, luego se desecaron hasta un punto crítico y finalmente se recubrieron con oro. Resultados: las anteras son bitecas y están sostenidas por un largo filamento formado por un estrato epidérmico, tejido parenquimatoso y un haz vascular. La dehiscencia ocurre longitudinalmente a través del estomio. La pared de la antera madura está formada por una capa epidérmica monoestratificada, una capa de células endoteliales con engrosamientos fibrilares lignificados y se pueden apreciar restos celulares del tapete y abundantes orbículas recubriendo la cavidad de los microesporangios. Los tejidos epidérmicos y parenquimatosos de las anteras almacenan polifenoles. Las orbículas son generalmente esféricas, psiladas y exhiben las mismas reacciones de tinción y fluorescencia que la exina de los granos de polen. Los granos de polen son mónades, isopolares, pequeños $(16-19 \mu \mathrm{m})$ con amb circular, esferoidales, tricolpados con colpos medianos o cortos $(5-10 \mu \mathrm{m})$ con membrana ornamentada, semitectatos, reticulados, heterobrochados, las paredes del retículo ornamentadas o no, con microgránulos de diferente tamaño o escabrados. Los análisis estadísticos mostraron que existen diferencias significativas en el tamaño de los granos de polen $(\mathrm{P}<0.05)$. Se observa que los granos de polen más pequeños son los del genotipo TCS 19 (16.890 $\mu \mathrm{m})$ y se diferencian del resto de genotipos, y entre estos no se observan diferencias significativas. Solo dos genotipos (SCC 19 y SCA 6) presentaron polenkit y solo uno tiene paredes perforadas (SCA 6). Conclusiones: la estructura y micromorfología de las anteras de T. cacao son similares a las descritas para otras Malvaceae. Así mismo, los granos de polen mostraron variaciones de tamaño, ornamentación de las paredes y del lumen del retículo y presencia de polenkit. Sin embargo, no se observó relación entre las variaciones de los caracteres micromorfológicos analizados en los granos de polen y los modelos de compatibilidad polínica reportados para estos genotipos.

Palabras clave: cacao; microornamentación; esporopolenina; histoquímica; palinología; polenkit.

\section{REFERENCIAS}

Adjaloo, M.K., \& Oduro, W. (2013). Insect assemblage and the pollination system in cocoa ecosystems. Journal of Applied Biosciences, 62, 4582-4594.

Agudelo, C.G.A., Palencia, C.P.G.E., Antolinez, S.E.Y.E., \& Báez, D.E.Y. (2017). Nuevas variedades de cacao TCS (Theobroma Corpoica La Suiza) 13 y 19. Colombia: Corporación Colombiana de Investigación Agropecuaria, Minagriculatura. Recuperado de http:// hdl.handle.net/20.500.12324/11536

Aime, M.C., \& Phillips-Mora, W. (2005). The causal agents of witches' broom and frosty pod rot of cacao (chocolate, Theobroma cacao) form a new lineage of Marasmiaceae. Mycologia, 97(5), 1012-1022.

Alean, J., Chejne, F., Ramírez, S., Rincón, E., AlzateArbelaez, A.F., \& Rojano, B. (2020). Proposal of a method to evaluate the in-situ oxidation of polyphenolic during the cocoa drying. Drying Technology, 1-12. DOI: $10.1080 / 07373937.2020 .1817933$

Amirul-Aiman, A.J., Noraini, T., Nurul-Aini, C.A.C., Chung, R., Phupumirat, W., Ruzi, A., ... Suhaniza, R. (2019). Pollen morphology and harmomegathic characters of Byttneria Löfl. Species (Sterculiaceae s.s subfam. Byttnerioideae). Malaysian Applied Biology, 48(3), 19-26.

Aoun, M. (2017). Host defense mechanisms during fungal pathogenesis and how these are overcome in susceptible plants: A review. International Journal of Botany, 13, 82-102.

Aoun, M., Rioux, D., Simard, M., \& Bernier, L. (2009). Fungal colonization and host defense reactions in Ulmus americana callus cultures inoculated with Ophiostoma novo-ulmi. Phytopathology, 99, 642-650.

Baker, H.G. \& Baker, I. (1979). Starch in Angiosperm pollen grains and its evolutionary significance. American Journal of Botany, 66(5), 591-600.

Bartley, B.G.D. (2005) The genetic diversity of cacao and its utilization. Wallingford, UK: CABI Publishing.

Bayer, C., Fay, M.F., De bruijn, A.Y., Savolainen, V., Morton, C.M., Kubitzki, K., ... Chase, M.W. (1999). Support for an expanded family concept of Malvaceae within a recircumscribed order Malvales: A combined analysis of plastid atp B and rbc L DNA sequences. Botanical Journal of the Linnean Society, 129(4), 267-303.

Bayer, C., \& Kubitzki, K. (2003). Malvaceae. In K. Kubitzki (Ed.), The families and genera of vascular plants (pp. 225-31). Germany: Springer-Verlag. 
Beg, M.S., Ahmad, S., Jan, K., \& Bashir, K. (2017). Status, supply chain and processing of Cocoa-a review. Trends in Food Science \& Technology, 66, 108-116.

Bhattacharjee, R. (2018). Taxonomy and classification of cacao. In P. Umaharan (Ed.), Achieving sustainable cultivation of cocoa (pp. 1-16). London, England: Burleigh Dodds Science Publishing.

Bibi, N., Naveed, A., Manzoor, H., \& Ajab, K.M. (2010). Systematic implications of pollen morphology in the family Malvaceae from North West frontier province, Pakistan. Pakistan Journal of Botany, 42, 2205-2214.

Bridgemohan, P., Singh, K., Cazoe, E., Perry, G., Mohamed, A., \& Bridgemohan, S.H.R. (2017). Cocoa floral phenology and pollination: Implications for productivity in Caribbean Islands. Journal of Plant Breeding and Crop Science, 9(7), 106-117.

Carrizo, C.C. (2002). An approach to the diversity of endothecial thickenings in Solanaceae. Flora-Morphology, Distribution, Functional Ecology of Plants, 197(3), 214-223.

Corporación Colombiana de Investigación Agropecuaria (2014a). Clon de Cacao TCS 01: Theobroma Corpoica La Suiza 01. Recuperado de https://repository. agrosavia.co/handle/20.500.12324/34650

Corporación Colombiana de Investigación Agropecuaria. (2014b). Clon de Cacao TCS 06: Theobroma Corpoica La Suiza 06. Recuperado de http://hdl.handle. net/20.500.12324/34651

Counet, C., Ouwerx, C., Rosoux, D., \& Collin, S. (2004). Relationship between procyanidin and flavor contents of cocoa liquors from different origins. Journal of Agricultural and Food Chemistry, 52(20), 6243-6249.

Chumacero de Schawe, C.C., Kessler, M., Hensen, I., \& Tscharntke, T. (2018). Abundance and diversity of flower visitors on wild and cultivated cacao (Theobroma cacao L.) in Bolivia. Agroforestry Systems, 92(1), 117-125.

Crang, R., Lyons-Sobaski, S., \& Wise, R. (2018). Plant Anatomy: A Concept-Based Approach to the Structure of Seed Plants. Cham, Switzerland: Springer.

Dawson, J., Sözen, E., Vizir, I., Van Waeyenberge, S., Wilson, Z.A., \& Mulligan, B.J. (1999). Characterization and genetic mapping of a mutation (ms35) which prevents anther dehiscence in Arabidopsis thaliana by affecting secondary wall thickening in the endothecium. New Phytologist, 144(2), 213-222.

de Almeida, A.A., \& Valle, R.R. (2010). Cacao: ecophysiology of growth and production. In F. Damatta (Ed.), Ecophysiology of Tropical Tree Crops (pp. 37-70). New York, USA: Nova Science Publishers, Inc. ed. Soil Science Society of America. de Jesus Branco, S.M., da Silva, D.V., Lopes, U.V., \& Corrêa, R.X. (2018). Characterization of the sexual self-and cross-compatibility in genotypes of cacao. American Journal of Plant Sciences, 9(9), 1794-1806.

de Souza, A.P., Moreira, F.L., Sarmento, H.A.D., \& da Costa, B.F. (2018). Cacao-Theobroma cacao. In S. Rodrigues, E.S. de Oliveira, \& E.S. de Brito (Eds.), Exotic Fruits reference guide (pp. 69-76). London, UK: Academic Press.

Demarco, D. (2017). Histochemical analysis of plant secretory structures. In C. Pellicciari \& M. Biggiogera (Eds.), Histochemistry of single molecules methods and protocols (pp. 313-330). New York, USA: Humana Press.

Elwers, S., Zambrano, A., Rohsius, C., \& Lieberei, R. (2010). Histological features of phenolic compounds in fine and bulk cocoa seed (Theobroma cacao L.). Journal of Applied Botany and Food Quality, 83(2), 182-188.

Enríquez, G.A. (1985). Curso sobre el cultivo del cacao. Turrialba, Costa Rica: Centro Agronómico Tropical de Investigación y Enseñanza (CATIE).

Erdtman, G. (1986) Pollen Morphology and Plant Taxonomy. Angiosperms. Amsterdam, Netherlands: Brill Verlag.

Ford, C.S., \& Wilkinson, M.J. (2012). Confocal observations of late-acting self-incompatibility in Theobroma cacao L. Sexual Plant Reproduction, 25(3), 169-183.

French, J.C. (1985). Patterns of endothecial wall thickenings in Araceae: subfamilies Pothoideae and Monsteroideae. American Journal of Botany, 72(3), 472-486.

Frimpong-Anin, K., Adjaloo, M.K., Kwapong, P.K., \& Oduro, W. (2014). Structure and stability of cocoa flowers and their response to pollination. Journal of Botany, 2014, 1-6.

Furness, C.A., \& Rudall, P.J. (2001). The tapetum in basal angiosperms: early diversity. International Journal of Plant Sciences, 162(2), 375-392.

Galati, B.G. (2003). Ubisch bodies in Angiosperms. Advance Plant Reproduction Biology, 2, 1-20.

Galati, B.G., Gotelli, M.M., Dolinko, A.E., \& Rosenfeldt, S. (2019). Could microechinate orbicules be related to the release of pollen in anemophilous and 'buzz pollination'species? Australian Journal of Botany, 67(1), 16-35.

Galati, B.G., Gotelli, M.M., Rosenfeldt, S., Torretta, J.P., \& Zarlavsky, G. (2011). Orbicules in relation to the pollination modes. In B.J. Kaiser (Ed.), Pollen: structure, $y$ types and effects (pp. 1-15). New York, USA: Nova Science Publisher. 
Galati, B.G., Monacci, F., Gotelli, M.M., \& Rosenfeldt, S. (2007). Pollen, tapetum and orbicule development in Modiolastrum malvifolium (Malvaceae). Annals of Botany, 99(4), 755-763.

Galati B.G., \& Rosenfeldt, S. (1998). The pollen development in Ceiba insignis (Kunth) Gibbs and Semir ex Chorisia speciosa St Hil. (Bombacaceae). Phytomorphology, 48, 121-129.

Gallego, R.A.M., Henao, R.A.M., Urrea, T.A.I., \& Atehortua, G.L. (2016). Polyphenols distribution and reserve substances analysis in cacao somatic embryogenesis. Acta Biológica Colombiana, 21(2), 335-345.

García, T.B., Bazurto, Z.A., García, C.L., \& Zambrano, G.F. (2019). Morphology, viability, and longevity of pollen of National Type and Trinitarian (CCN-51) clones of cocoa (Theobroma cacao L.) on the coast of Ecuador. Brazilian Journal of Botany, 42(3), $441-448$

Garcia, T.B., Potiguara, R.C.D.V., Kikuchi, T.Y.S., Demarco, D., \& Aguiar-Dias, A.C.A.D. (2014). Leaf anatomical features of three Theobroma species (Malvaceae $s l$ ) native to the Brazilian Amazon. Acta Amazonica, 44(3), 291-300.

García, C.L.C., Vera, P.L., Zambrano, G.F., Zamora, M.A., \& Cedeño, O.J. (2020). Pollen production in Theobroma cacao L. genotypes national type and CCN-51 and its relationship with climatic factors on the ecuadorian coast. Acta Agrobotanica, 73(2), 1-9.

Gotelli, M.M., Galati, B.G., \& Medan, D. (2008). Embryology of Helianthus annuus (Asteraceae). Annales Botanici Fennici, 45(2), 81-96.

Gotelli, M.M., Galati, B.G., \& Zarlavsky, G. (2016). Pollen development and anther morphology in 14 species of Rhamnaceae. Plant Systematics and Evolution, 302(10), 1433-1444.

Ha, L.T.V., Hang, P.T., Everaert, H., Rottiers, H., Anh, L.P.T., Dung, T.N., ... Messens, K. (2016). Characterization of leaf, flower, and pod morphology among Vietnamese cocoa varieties (Theobroma cacao L.). Pakistan Journal Botany, 48(6), 2375-2383.

Halbritter, H. (1998). Preparing living pollen material for scanning electron microscopy using 2,2-dimethoxypropane (DMP) and critical-point drying. Biotechnic \& Histochemistry, 73(3), 137-143.

Halbritter, H., \& Buchner, R. (2016). Theobroma cacao. In: PalDat - A palynological database. Recuperado de https://www.paldat.org/pub/ Theobroma_cacao/301733

Halbritter, H., Ulrich, S., Grimsson, F., Weber, M., Zetter, R., Hesse, M., ... Frosch-Radivo, A. (2018). Illustrated pollen terminology. Cham, Switzerland: Springer.
Hamdy, R., \& Shamso, E. (2010). Pollen morphology of Sterculiaceae (s. str.) in Egypt and its taxonomic significance. Egyptian Journal of Botany, 50, 103-117.

Heslop-Harrison, J. (1968). Pollen wall development. Science, 161(3838), 230-237.

Huysmans, S., El-Ghazaly, G., Nilsson, S., \& Smets, E. (1997). Systematic value of tapetal orbicules: a preliminary survey of the Cinchonoideae (Rubiaceae). Canadian Journal of Botany, 75, 815-826.

Huysmans, S., El-Ghazaly, G., \& Smets, E. (1998). Orbicules in angiosperms: morphology, function, distribution, and relation with tapetum types. The Botanical Review, 64(3), 240-272.

Ioannone, F., Di Mattia, C.D., De Gregorio, M., Sergi, M., Serafini, M., \& Sacchetti, G. (2015). Flavanols, proanthocyanidins and antioxidant activity changes during cocoa (Theobroma cacao L.) roasting as affected by temperature and time of processing. Food Chemistry, 174, 256-262.

Kaufmann, T. (1975). Ecology and behavior of cocoa pollinating Ceratopogonidae in Ghana, W. Africa. Environmental Entomology, 4(2), 347-351.

Konyar, S.T., Dane, F., \& Tütüncü, S. (2013). Distribution of insoluble polysaccharides, neutral lipids, and proteins in the developing anthers of Campsis radicans (L.) Seem. (Bignoniaceae). Plant Systematics and Evolution, 299(4), 743-760.

Lanaud, C., Fouet, O., Legavre, T., Lopes, U., Sounigo, O., Eyango, M.C., ... Gyapay, G. (2017). Deciphering the Theobroma cacao self-incompatibility system: from genomics to diagnostic markers for self-compatibility. Journal of Experimental Botany, 68(17), 4775-4790.

Lattanzio, V., Lattanzio, M.T.V., \& Cardinali, A. (2006). Role of phenolics in the resistance mechanisms of plants against fungal pathogens and insects. In F. Imperato (Ed.), Phytochemistry: Advances in Research (pp. 23-67). India: Research Signpost.

Lattar, E., Galati, B.G., \& Ferrucci, M.S. (2014). Comparative study of anther development, microsporogenesis and microgametogenesis in species of Corchorus, Heliocarpus, Luehea and Triumfetta (Malvaceae: Grewioideae) from South America. New Zealand Journal of Botany, 52(4), 429-445.

López, H.J.G., López, H.L.E., Avendaño, A.C.H., Aguirre, M.J.F., Espinosa, Z.S., Moreno, M.J.L., ... Suárez, V.G.M. (2018). Biología floral de cacao (Theobroma cacao L.); criollo, trinitario y forastero en México. Agroproductividad, 11(9), 129-136.

Magrone, T., Russo, M.A., \& Jirillo, E. (2017). Cocoa and dark chocolate polyphenols: from biology to clinical applications. Frontiers in Immunology, 8, 677-690. 
Mambrín, M.V., Avanza, M.M., \& Ferrucci, M.S. (2010) Análisis morfológico y morfométrico del polen de Corchorus, Heliocarpus, Luehea, Mollia y Triumfetta (Malvaceae, Grewioideae) en la región austral de América del Sur. Darwiniana, 48(1), 45-58.

Manning, J.C. (1996). Diversity of endothecial patterns in the angiosperms. In W.G.D. Arcy, \& R.C. Keating (Eds.), The anther: form, function and phylogeny (pp. 136-158). Cambridge, England: University of Cambridge Press Syndicate.

Manning, J.C., \& Linder, H.P. (1990). Cladistic analysis of patterns of endothecial thickenings in the Poales/ Restionales. American Journal of Botany, 77(2), 196-210.

Martini, M.H., Figueira, A., Lenci, C.G., \& Tavares, D.D.Q. (2008). Polyphenolic cells and their interrelation with cotyledon cells in seven species of Theobroma (Sterculiaceae). Brazilian Journal of Botany, 31(3), 425-431.

Moon, H.K. (2018). The phylogenetic potential of orbicules in angiosperms. Korean Journal of Plant Taxonomy, 48(1), 9-23.

Motamayor, J.C., Lachenaud, P., Mota, J.W.D.S., Loor, R., Kuhn, D.N., Brown, J.S., \& Schnell, R.J. (2008). Geographic and genetic population differentiation of the Amazonian chocolate tree (Theobroma cacao L). PloS One, 3(10), 1-8.

Motamayor, J.C., Lachenaud, P., Da Silva e Mota, J.W., Loor, R.G., Martinez, W.J., Graham, J., ... Schnell, R.J. (2010). No mas forastero: a new protocol for meaningful cacao germplasm classification. In Proceedings of the 16th international cocoa research conference (pp. 179-185). Nigeria: COPAL.

Nair, K.P. (2010). The agronomy and economy of important tree crops of the developing world. Burlington, USA: Elsevier.

Nakamura, A.T., Longhi-Wagner, H.M., \& Scatena, V.L. (2010). Anther and pollen development in some species of Poaceae (Poales). Brazilian Journal of Biology, 70(2), 351-360.

Narayanapur, V.B., Suma, B., \& Minimol, J.S. (2018). Self-incompatibility: a pollination control mechanism in plants. International Journal of Plant Sciences (Muzaffarnagar), 13(1), 201-212.

Niemenak, N., Rohsius, C., Elwers, S., Ndoumou, D.O., \& Lieberei, R. (2006). Comparative study of different cocoa (Theobroma cacao L.) clones in terms of their phenolics and anthocyanins contents. Journal of Food Composition and Analysis, 19(6-7), 612-619.

N'Zi, J.C., Kahia, J., Diby, L., \& Kouamé, C. (2017). Compatibility of ten elite cocoa (Theobroma cacao L.) clones. Horticulturae, 3(3), 1-8.
Oracz, J., Zyzelewicz, D., \& Nebesny, E. (2015). The content of polyphenolic compounds in cocoa beans (Theobroma cacao L.), depending on variety, growing region, and processing operations: a review. Critical Reviews in Food Science and Nutrition, 55(9), 1176-1192.

Osorio, G.J.A., Berdugo, C.J., Coronado, R.A., Zapata, Y.P., Quintero, C., Gallego, S.G., \& Yockteng, R. (2017). Colombia a source of cacao genetic diversity as revealed by the population structure analysis of germplasm bank of Theobroma cacao L. Frontiers in Plant Science, 8, 1-13.

Pacini, E. (2010). Relationships between tapetum, loculus, and pollen during development. International Journal of Plant Sciences, 171(1), 1-11.

Pacini, E., \& Franchi, G.G. (1988). Amylogenesis and amylolysis during pollen grain development. In M. Cresti, P. Gori, \& E. Pacini (Eds.), Sexual Reproduction in Higher Plant (pp. 181-186). Germany: Springer-Verlag.

Pacini, E., Franchi, G.G., \& Hesse, M. (1985). The tapetum: Its form, function, and possible phylogeny in Embryophyta. Plant Systematics and Evolution, 149(3-4), 155-185.

Pacini, E., Guarnieri, M., \& Nepi, M. (2006). Pollen carbohydrates and water content during development, presentation, and dispersal: a short review. Protoplasma, 228(1-3), 73 .

Pacini, E., \& Hesse, M. (2005). Pollenkitt-its composition, forms and functions. Flora-Morphology, Distribution, Functional Ecology of Plants, 200(5), 399-415.

Parkinson, B.M., \& Pacini, E. (1995). A comparison of tapetal structure and function in pteridophytes and angiosperms. Plant Systematics and Evolution, 198(1-2), 55-88.

Passarelli, L., \& Cocucci, A.A. (2006). Morphological and functional aspects of anthers from species of Solanum sect. Cyphomandropsis. Phytomorphology, $56(1-2), 1-8$.

Perveen, A., Grafström, E., \& El-Ghazaly, G. (2004). World Pollen and Spore Flora 23. Malvaceae Adams. Pp. Subfamilies: Grewioideae, Tilioideae, Brownlowioideae. Grana, 43(3), 129-155.

Perveen, A., \& Qaiser, M. (2009). Pollen flora of PakistanMalvaceae: Dombeyoideae-Lxii. Pakistan Journal of Botany, 41(2), 491-494.

Pipitone, L. (2016). Overview of cocoa supply and demand. In International Cocoa Organization (ICCO). ICCO Cocoa Market Outlook Conference September. England: International Cocoa Organization (ICCO).

Porter, L.J., Ma, Z., \& Chan, B.G. (1991). Cacao procyanidins: major flavanoids and identification of 
some minor metabolites. Phytochemistry, 30(5), $1657-1663$

Punt, W., Hoen, P.P., Blackmore, S., Nilsson, S., \& Le Thomas, A. (2007). Glossary of pollen and spore terminology. Review of Palaeobotany and Palynology, 143(1-2), 1-83.

Rangel, F.M.A., Zavaleta, M.H.A., Córdova, T.L., López, A.A.P., Delgado, A.A., Vidales, F.I., \& Villegas, M.Á. (2012). Anatomía e histoquímica de la semilla del cacao (Theobroma cacao L.) criollo mexicano. Revista Fitotecnia Mexicana, 35(3), 189-197.

Richardson, J.E., Whitlock, B.A., Meerow, A.W., \& Madriñán, S. (2015). The age of chocolate: a diversification history of Theobroma and Malvaceae. Frontiers in Ecology and Evolution, 3, 1-14.

Rincón, B.E.J., Grisales. E.C., Cuaran, V.L., \& Cardona, N.L. (2020). Alteraciones anatómicas e histoquímicas ocasionadas por la oidiosis en hojas de Hydrangea macrophylla (Hydrangeaceae). Revista de Biología Tropical, 68(3), 959-976.

Rojas, L.F., Londoño, J., Gallego, A.M., Herrera, A.L., Aguilera, C., \& Atehortúa, L. (2008). Total polyphenols analysis of mature seeds and tissue cultures of some Colombian cocoa varieties. Actualidades Biológicas, 30(89), 117-123.

Roth, I., \& Lindorf, H. (1971). Desarrollo y anatomía del fruto y de la semilla de Theobroma cacao L. Acta Botánica Venezuélica, 6(1), 261-295.

Ruggiero, F., \& Bedini, G. (2020). Phylogenetic and morphologic survey of orbicules in angiosperms. Taxon, 69(3), 543-566.

Ruzin, S.E. (1999). Plant microtechnique and microscopy. Nueva York, USA: Oxford University.

Saba, M.D., \& dos Santos, F.D.A.R. (2015). Pollen morphology and exine ultrastructure of selected species of Waltheria L. (Byttnerioideae-Malvaceae). Review of Palaeobotany and Palynology, 221, 204-210.

Santos, R.C., Pires, J.L., \& Correa, R.X. (2012). Morphological characterization of leaf, flower, fruit and seed traits among Brazilian Theobroma L. species. Genetic Resources and Crop Evolution, 59(3), 327-345.

Santos de Oliveira, J.M., Martins, M.S., Dorneles, M.P., \& Carvalho de Freitas, C. (2015). Starch distribution in anthers, microspores and pollen grains in Aechmea recurvata (Klotzsch.) LB Sm., Dyckia racinae LB Sm. and Tillandsia aeranthos (Loisel.) LB Sm. (Bromeliaceae). Acta Botanica Brasilica, 29(1), 103-112.

Shamrov, I.I., Anisimova, M.G., \& Babro, A.A. (2020). Early stages of anther development in flowering plants. Botanica Pacifica, 9(2), 1-10.
Silveira Júnior, C.E.A, Lima, L.L.C., \& Saba, M.D. (2017). Pollen morphology of Waltheria L. (MalvaceaeByttnerioideae) from Bahia, Brazil. Acta Botanica Brasilica, 31(4), 597-612.

Simpson, M.G. (2010). Plant systematics. San Diego, USA: Academic Press.

Sivachandran, R., Gnanam, R., Sudhakar, D., Suresh, J., \& Ram, S.G. (2017). Influence of genotypes, stages of microspore, pre-treatments and media factors on induction of callus from anthers of cocoa (Theobroma cacao L.). Journal of Plantation Crops, 45(3), 162-172.

Squicciarini, M.P., \& Swinnen, J. (2016) The Economics of Chocolate. Oxford, UK: Oxford University Press.

Strittmatter, L.I., \& Galati, B.G. (2001). Development of anthers, microsporogenesis and

microgametogenesis of Myosotis azorica and M. laxa (Boraginaceae). Phytomorphology, 51(1), 1-10.

Strittmatter, L.I, Galati, B.G., \& Monacci, F. (2000). Ubisch bodies in the peritapetal membrane of $\mathrm{Abu}$ tilon pictum Gill (Malvaceae). Beiträge zur Biologie der Pflanzen, 71, 1-10.

Swanson, J.D., Carlson, J.E., \& Guiltinan, M.J. (2008). Comparative flower development in Theobroma cacao based on temporal morphological indicators. International Journal of Plant Sciences, 169(9), 1187-1199.

Tang, Y.A., Gao, H.U.I., Wang, C.M., \& Chen, J.Z. (2006). Microsporogenesis and microgametogenesis of Excentrodendron hsienmu (Malvaceae sl) and their systematic implications. Botanical Journal of the Linnean Society, 150(4), 447-457.

Tang, Y., Gao, H., \& Xie, J.S. (2009). An embryological study of Eriolaena candollei Wallich (Malvaceae) and its systematic implications. Flora-Morphology, Distribution, Functional Ecology of Plants, 204(8), 569-580.

Tebbitt, M.C., \& Maciver, C.M. (1999). The systematic significance of the endothecium in Begoniaceae. Botanical Journal of the Linnean Society, 131(3), 203-221.

Verstraete, B., Moon, H.K., Smets, E., \& Huysmans, S. (2014). Orbicules in flowering plants: a phylogenetic perspective on their form and function. The Botanical Review, 80(2), 107-134.

Wei, D., Xu, H., \& Li, R. (2015). Dynamics of polysaccharides and neutral lipids during anther development in castor (Ricinus communis). Journal of the American Society for Horticultural Science, 140(4), 356-361. 
Wickramasuriya, A.M., \& Dunwell, J.M. (2018). Cacao biotechnology: current status and future prospects. Plant Biotechnology Journal, 16(1), 4-17.

Wilson, Z.A., Song, J., Taylor, B., \& Yang, C. (2011). The final split: the regulation of anther dehiscence. Journal of Experimental Botany, 62(5), 1633-1649.

Yeung, E.C.T., Stasolla, C., Sumner, M.J., \& Huang, B.Q. (2015). Plant microtechniques and protocols. New York, USA: Springer.

Young, A.M., Erickson, E.H., Strand, M.A., \& Erickson, B.J. (1987). Pollination biology of Theobroma and Herrania (Sterculiaceae)- 1. Floral biology. International Journal of Tropical Insect Science, 8(2), 151-164.

Young, A.M., Schaller, M., \& Strand, M. (1984). Floral nectaries and trichomes in relation to pollination in some species of Theobroma and Herrania (Sterculiaceae). American Journal of Botany, 71(4), 466-480.

Young, A.M., \& Severson, D.W. (1994). Comparative analysis of steam distilled floral oils of cacao cultivars (Theobroma cacao L., Sterculiaceae) and attraction of flying insects: Implications for a Theobroma pollination syndrome. Journal of Chemical Ecology, 20(10), 2687-2703.

Yun, Z., \& Huiqiao, T. (2015). The distribution features of polysaccharides and lipids in the development of tomato anthers. Horticultural Plant Journal, 1(1), $35-40$.

Zhang, D., Martínez, W.J., Johnson, E.S., Somarriba, E., Phillips-Mora, W., Astorga, C., ... Meinhardt, L.W. (2012). Genetic diversity and spatial structure in a new distinct Theobroma cacao L. population in Bolivia. Genetic Resources and Crop Evolution, 59(2), 239-252.

Zhang, D., \& Motilal, L. (2016). Origin, dispersal, and current global distribution of cacao genetic diversity. In B.A. Bailey \& L.W. Meinhardt (Eds.), Cacao diseases a history of old enemies and new encounters (pp. 3-32). Switzerland: Springer International Publishing.

Zheng, R., Su, S., Xiao, H., \& Tian, H. (2017). Polysaccharides and lipids in the developing anthers of Hong Kong orchid tree (Bauhinia blakeana). Trees, 31(4), 1295-1301. 